\title{
Comparison of operative procedures for re-leaks duodenal perforation: a cross-sectional analysis from a tertiary care hospital in a developing country
}

\author{
Saurabh S. Sanjanwala ${ }^{1}$, Vinaykumar N. Thati ${ }^{1 *}$, Omprakash S. Rohondia $^{2}$, \\ Samir U. Rambhia ${ }^{1}$
}

${ }^{1}$ Department of Surgery, H.B.T Medical College and Dr. R.N. Cooper Mun. General Hospital, Juhu, Mumbai, India ${ }^{2}$ Department of Surgery, MGM Hospital, Parel, Mumbai, India

Received: 02 July 2016

Accepted: 07 July 2016

*Correspondence:

Dr. Vinaykumar Thati,

E-mail: drvinaythati@gmail.com

Copyright: (c) the author(s), publisher and licensee Medip Academy. This is an open-access article distributed under the terms of the Creative Commons Attribution Non-Commercial License, which permits unrestricted non-commercial use, distribution, and reproduction in any medium, provided the original work is properly cited.

\begin{abstract}
Background: Re-leaks following surgical closure of duodenal perforations is a well known entity. Considering the paucity of data on patients with re-leak from Indian population, the present study was carried out.

Methods: The present study is a prospective audit of patients diagnosed with duodenal re-leak and surgical procedures for arresting the leak was done. Hospital indoor case records were reviewed from 2005 to 2010. Following details were collected: demographic details (age and sex); presenting complaints; success of the surgical procedures to arrest re-leak and overall survival of patients. Conservative measures, 3 tubes method, jejunal patch, $\mathrm{T}$ tube duodenostomy and rohondia's cholecystoduodenoplasty were the type of procedures routinely performed for such patients. Descriptive statistics was used to represent various variables-mean (SD) for continuous and proportions (percentages) for categorical variables.

Results: A total of 41 patients with duodenal re-leak requiring intervention were identified with mean (range) of age in years of 45 (25-65). The following types of procedures were carried out to arrest duodenal re-leaks: 3 tubes method (4/41, 9.8\%), jejunal patch (7/41, 17.1\%), $T$ tube duodenostomy (1/41, 2.4\%) and Rohondia's cholecystoduodenoplasty $(16 / 41,39 \%)$ and conservative $(13 / 41,31.7 \%)$. A total of $75 \%(12 / 16)$ success in stopping the leak was observed with Rohondia's cholecystoduodenoplasty followed by $1 / 4$ (25\%) with 3 tubes duodenostomy, one each with jejunal patch $(14.3 \%)$ and conservative techniques $(7.7 \%)$ and none with $\mathrm{T}$ - tube duodenostomy (P-0.1; not significant). A total of 32/41 (78\%) patients died following the surgery for duodenal re-leak of which nearly fourfifths of them $(26 / 32,81 \%)$ died due to septicaemia, $5 / 33(15.2 \%)$ had pulmonary complications and $1 / 33(3 \%)$ due to perforation.

Conclusions: To conclude, the present study gives baseline data on patients who have undergone various surgical procedures for arresting duodenal perforation but had re-leaks, in a tertiary care hospital of a developing country. The better outcomes associated with Rohondia's cholecystoduodenoplasty was found in comparison to other surgical and conservative measures.
\end{abstract}

Keywords: 3 Tubes method, Jejunal patch, T tube duodenostomy, Cholecystoduodenoplasty

\section{INTRODUCTION}

Gastro-duodenal perforations are common and usually arise as a complication of peptic ulcer disease and $90 \%$ have been documented to occur in duodenum. ${ }^{1}$ The annual incidence rates of peptic ulcer disease were 0.10 $0.19 \%$ for physician-diagnosed and $0.03-0.17 \%$ based on hospitalization data. ${ }^{2}$ Peptic ulcer perforation is a serious 
complication affecting almost 2-10\% of peptic ulcer patients. ${ }^{3,4}$ In fact, a recent systematic review of various studies found a12.2\% (95\% CI: 2.5-21.9) average longterm recurrence of perforation. ${ }^{5}$ A study in the Netherlands estimated the per person costs of perforation of EUR 19,000. ${ }^{6}$ One third of patients with perforation undergoing surgical interventions have been reported to have some complications. ${ }^{7}$ An average mortality of $23.5 \%$ (95\% CI: 15.5-31.0) was observed due to perforation from a meta-analysis. ${ }^{5}$ Longer duration of perforation symptoms of more than 4 days and age $>30$ years were found to be risk factors of mortality in perforated patients. ${ }^{8}$ Considering the paucity of outcome studies on perforated peptic ulcer disease in Indian population, the present study was carried out as an observational study.

\section{METHODS}

\section{Study ethics}

The present study was a retrospective review of indoor case records of patients who were diagnosed with re-leak following surgery for duodenal ulcers. The study was carried out after obtaining approval from institutional ethics committee and a waiver for informed consent was obtained. The study was carried out in accordance with the declaration of Helsinki 2008 ethical guidelines for conducting research on human beings.

\section{Study procedure}

The study was carried out as a prospective audit. Case records of patients from 2005 to 2010 diagnosed as duodenal re-leak for which surgical procedures for arresting was done, were scrutinized and the following data were collected: demographic details (age and sex); presenting complaints; success of surgical procedures to arrest re-leak and overall survival of the patients. Conservative measures, 3 tubes method, jejunal patch, T tube duodenostomy and Rohondia's cholecystoduodenoplasty (RCD) were the procedures routinely performed for such patients.

\section{Statistical tests}

Descriptive statistics was used to represent various variables-mean (SD) for continuous and proportions (percentages) for categorical variables. Chi-square test for association was used to analyze the difference in success and mortality between different surgical procedures.

\section{RESULTS}

\section{Demographic details}

A total of 41 patients with duodenal re-leak requiring intervention were identified with mean (range) of age in years of 45 (25-65). Of these 41 patients, 25 (61\%) were males and $16(39 \%)$ were females. Abdominal pain was the most common complaint observed in 34/41 (83\%) patients (Figure 1).

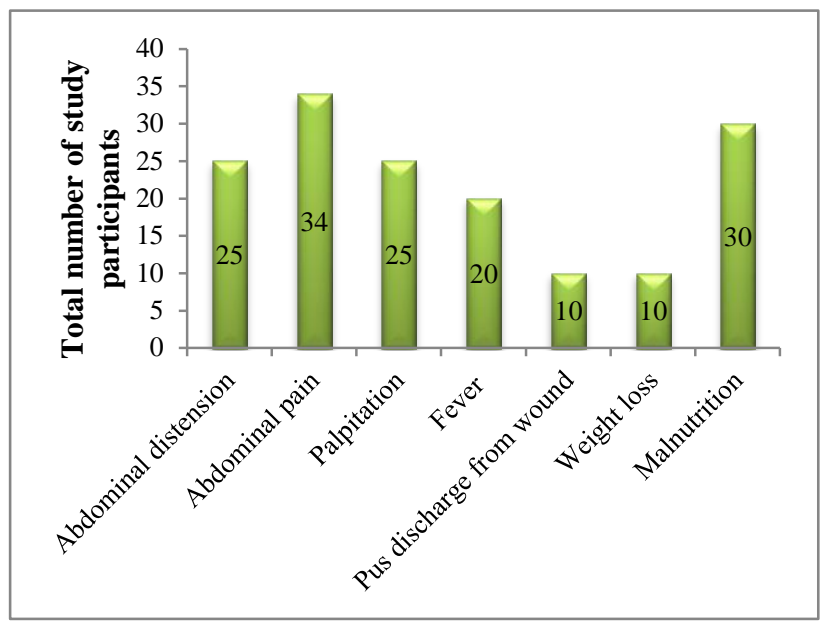

Figure 1: Presenting complaints of the study participants $(\mathrm{N}=41)$.

\section{Surgical interventions carried out for arresting duodenal re-leaks}

The following types of procedures were carried out to arrest duodenal re-leaks: 3 tubes method (4/41, 9.8\%), jejunal patch $(7 / 41,17.1 \%)$, T tube duodenostomy $(1 / 41$, $2.4 \%)$ and $\operatorname{RCD}(16 / 41,39 \%)$ and conservative (13/41, $31.7 \%$ ). Figure 2 depicts the proportions of the different surgical interventions carried out amongst study participants.

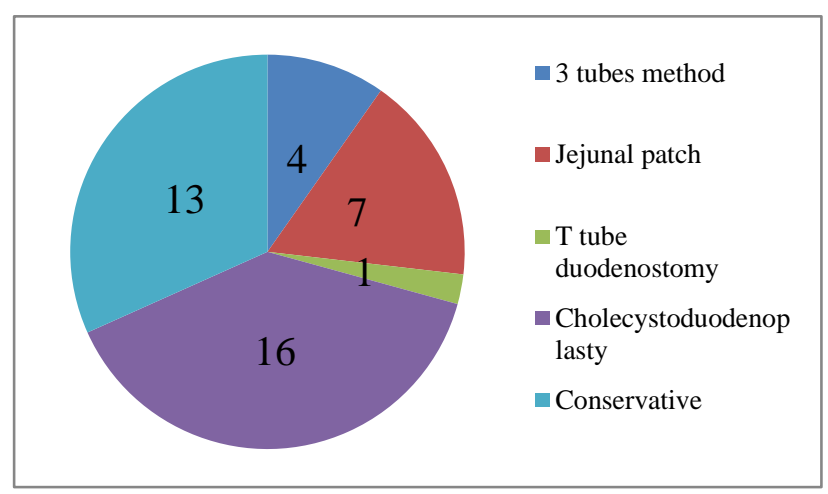

Figure 2: Surgical interventions carried out for arresting duodenal re-leaks.

\section{Outcomes of the procedures}

A total of $75 \%(12 / 16)$ success in stopping the leak was observed with RCD followed by $1 / 4$ (25\%) with 3 tubes duodenostomy, one each with jejunal patch (14.3\%)and conservative techniques $(7.7 \%)$ and, none with $\mathrm{T}$ tube duodenostomy (P-0.1; not significant). Figure 3 depicts the success achieved with various surgical interventions.

A total of 32/41 (78\%) patients died following surgery for duodenal re-leak of which nearly four-fifths of them 
$(26 / 32,81 \%)$ died due to septicaemia, 5/33 (15.2\%) had pulmonary complications and $1 / 33$ (3\%) due to perforation. As regards the type of procedures, all patients who were performed either a jejunal patch or conservative treatment died followed by $3 / 4$ (75\%) who underwent 3 tubes duodenostomy, 8/16 (50\%) who were performed RCD and one with $\mathrm{T}$ tube duodenostomy died (P-0.1; not significant). Figure 4 depicts the mortality of various interventions carried out amongst study participants.

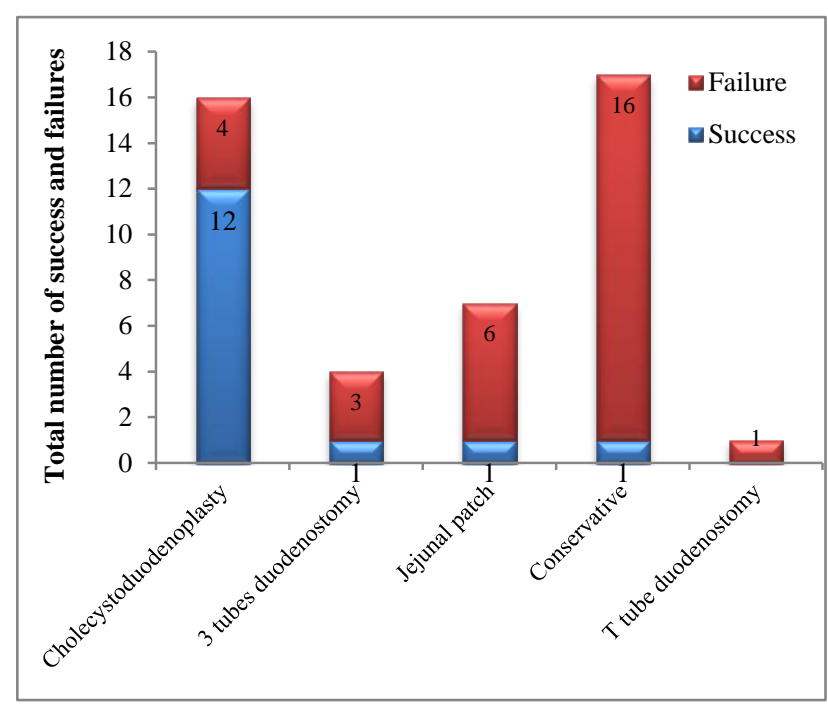

Figure 3: Success with various types of interventions amongst study participants.

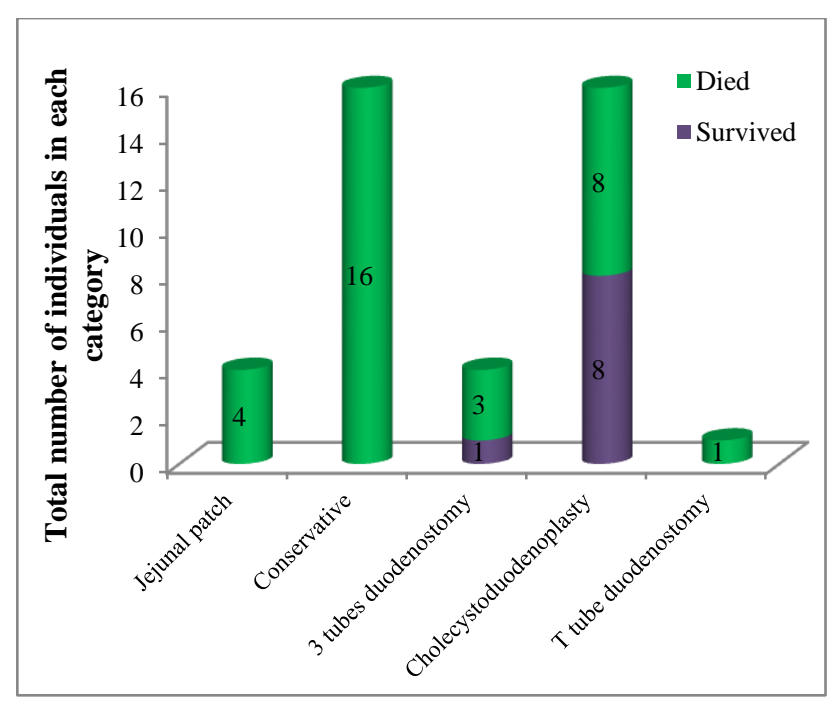

Figure 4: Mortality of the interventions carried out in study participants.

\section{DISCUSSION}

An observational study was carried out on the patients with duodenal perforations who had re-leaks from the sutured site. A total of 41 patients were identified and RCD was the most commonly done surgical procedure followed by conservative method, jejuna patch and 3 tubes method. Similarly success rate was also higher with RCD followed by 3 tubes duodenostomy, jejunal patch, conservative techniques and unfortunately none with $\mathrm{T}$ tube duodenostomy. All the patients who were performed either a jejunal patch or conservative treatment died followed by 3/4thwho underwent 3 tubes duodenostomy, $8 / 16(50 \%)$ who were performed RCD and one with T tube duodenostomy.

Re-leaks following closure of ulcer perforation is a noted complication. The incidence of re-leak ranges between 4 and $16 \%$ in various studies (Table 1). Rose et al recommended conservative measures which involve administration of total parenteral nutrition with drainage of leaking site. ${ }^{12}$

It was found that the conservative measures were associated with cent percent mortality and only $1 / 16$ with complete resolution. Additionally, Hamby et al described a simple apposition procedure for arresting the re-leak but the inflammation and induration of the ulcer surroundings precludes this intervention. ${ }^{13}$ Poor level of success was also found in the present study contrasting with the results of Maghsoudiet al where the authors obtained a success of arresting the re-leak in $13 / 17$ patients. ${ }^{11}$ Similarly, we found higher mortality in contrast to Wakayama et al wherein the authors found a mortality of only $5 \% .{ }^{14}$ Both the failure and mortality rates can be attributed to more number of study participants who were managed conservatively in the study. But sub-group analysis showed a better outcome with RCD in comparison with other interventions.

Table 1. Proportion of patients with re-leaks in various studies.

\begin{tabular}{|ll|}
\hline Study Id & $\begin{array}{l}\text { Number (percentage) of re- } \\
\text { leaks amongst study } \\
\text { participants }\end{array}$ \\
\hline Chalya et al $^{9}$ & $4 / 25(16)$ \\
\hline Gupta et al $^{10}$ & $8 / 160(5)$ \\
\hline Maghsoudi H et al $^{11}$ & $17 / 422(4)$ \\
\hline
\end{tabular}

Size of the perforation has been associated with risk of re-leaks. Gupta et al found that 3/122 (2.46\%) perforations with the size less than $1 \mathrm{~cm}$ were re-leaking while 5/38 (13.16\%) with size ranging between 1 and 3 $\mathrm{cm}$ had re-leak. ${ }^{10}$ Similarly, the authors also observed a three times higher risk of mortality with larger size of the perforation.

The present study is limited in not having assessed the size of the perforation and correspondingly the association with failure and risk of mortality. Similarly, we did not assess the incidence of duodenal re-leak from the total number of procedures performed and shorter follow up of the study participants. To conclude, the present study has given a baseline data of patients who have undergone various surgical procedures for arresting duodenal perforation but had re-leaks, from a tertiary care 
hospital in a developing country. We found better outcomes associated with RCD in comparison to other surgical and conservative measures.

Funding: No funding sources

Conflict of interest: None declared

Ethical approval: The study was approved by the institutional ethics committee

\section{REFERENCES}

1. Etonyeaku AC, Agbakwuru EA, Akinkuolie AA, Omotola CA, Talabi AO, Onyia CU, et al. A review of the management of perforated duodenal ulcers at a tertiary hospital in South Western Nigeria. African Health Sciences. 2013;13:907-13.

2. Sung JJY, Kuipers EJ, Elserag HB. Systematic review: the global incidence and prevalence of peptic ulcer disease. Alimen Pharmaco Therap. 2009;29:938-46.

3. Testini M, Portincasa P, Piccinni G, Lissidini G, Pellegrini F, Greco L. Significant factors associated with fatal outcome in emergency open surgery for perforated peptic ulcer. World J Gastroenterol. 2003;9:2338-40.

4. Soll AH. Peptic ulcer and its complications. In Sleisinger and Fordtran's Gastrointestinal and Liver Disease: Pathophysiology, Diagnosis, Management. $6^{\text {th }}$ edition. Edited by: Feldman M, Scharschmidt BF, Sleisenger MH. Philadelphia, PA: W.B. Saunders; 1998:620-678.

5. Lau JY, Sung J, Hill C, Henerson C, Howden CW, Metz DC. Systematic review of the epidemiology of complicated peptic ulcer disease: incidence, recurrence, risk factors and mortality. Digestion. 2011;84:102-13.

6. Leest H, Dieten H, Tulder M, Lems WF, Dijkmans $\mathrm{BA}$, et al. Costs of treating bleeding and perforated peptic ulcers in the Netherlands. J Rheumatol. 2004;31:788-91.

7. Lohsiriwat V, Prapasrivorakul S, Lohsiriwat D. Perforated peptic ulcer: clinical presentation, surgical outcomes, and the accuracy of the Boey scoring system in predicting postoperative morbidity and mortality. World J Surg. 2009;33:805.

8. Moses JF, Hughes CD, Patel PB, Chao TE, Konneh SA, Jallabah TY, et al. Surgical outcomes for peptic ulcer: a prospective case series at an academic hospital in Monrovia, Liberia. African J Emerg Med. 2015;5:60-5.

9. Chalya PL, Mabula JB, Koy M, Mchembe MD, Jaka $\mathrm{HM}$, Kabangila R, et al. Clinical profile and outcome of surgical treatment of perforated peptic ulcers in Northwestern Tanzania: a tertiary hospital experience. World J Emergency Surg. 2011;6:31.

10. Gupta S, Kaushik R, Sharma R, Attri A. The management of large perforations of duodenal ulcers. BMC Surgery. 2005;5:15.

11. Maghsoudi H, Ghaffari A. Generalized peritonitis requiring re-operation after leakage of omental patch repair of perforated peptic ulcer. saudi journal of gastroenterology. Official J Saudi Gastroentero Asso. 2011;17:124-8.

12. Rose D. One hundred and fourteen fistulas of the GI tract treated with total parenteral nutrition. Surg Gynecol Obstetr. 1986;163:345-50.

13. Hamby LS, Zweng TN, Strodel WE. Perforated gastric and duodenal ulcer: an analysis of prognostic factors. Am Surg. 1993;59:319-23.

14. Wakayama T, Ishizaki Y, Mitsusada M, Takahashi S, Wada T, Fukushima Y, et al. Risk factors influencing the short-term results of gastroduodenal perforation. Surg Today. 1994;24:681-7.

Cite this article as: Sanjanwala SS, Thati VN, Rohondia OS, Rambhia SU. Comparison of operative procedures for re-leaks duodenal perforation: a cross-sectional analysis from a tertiary care hospital in a developing country. Int Surg J 2016;3:1314-7. 